\title{
NOTA SOBRE LOS LENGUAJES DE LA JURISPRUDENCIA, LA SOCIOLOGÍA Y LA ÉTICA, RETRIBUCIONISMO VS. UTILITARISMO*
}

\author{
Rodolfo Vázquez
}

ITAM, México

RESUMEN. A partir de una revisión crítica de algunas obras emblemáticas del filósofo del derecho mexicano Ulises SCHMILL, se aborda el debate recurrente entre retribucionismo y utilitarismo con respecto a la justificación del castigo y su relación con el poder. Se propone un tercer modelo, cooperativo y constructivista, a medio camino entre el absolutismo de una ética de la coacción y el subjetivismo de una ética de la responsabilidad. Desde este tercer modelo se procede a hacer una crítica al consecuencialismo de SCHMILL y a una propuesta alternativa a la del autor con respecto a los planteamientos de TUCÍDIDES y SHAKESPEARE.

Palabras clave: Sanción, retribucionismo, utilitarismo, absolutismo moral, subjetivismo, constructivismo y objetivismo mínimo.

\section{Note on Los lenguajes de la jurisprudencia, la sociología y la ética, Retributionism vs. Utilitarianism}

ABSTRACT. Taking as a starting point a critical review of Mexican legal philosopher Ulises SCHMILL'S emblematic writings, we consider the recurring debate concerning retributivism and utilitarianism regarding the justification behind punishment and its relationship with power. A third model, halfway between the absolutism of the ethics of punishment and the subjectivity of ethics of responsibility, is proposed. Such a model is both cooperative and constructivist. From this third model a critique of SCHMILL'S consequentialism can be made, which alongside THUCYDIDES and SHAKESPEARE'S approaches, allows us to arrive at an alternative proposal.

Keywords: Punishment, retributivism, constructivism, subjectivism, moral absolutism, objectivism

* Fecha de recepción: 4 de marzo de 2016. Fecha de aceptación: 21 de marzo de 2016.

Presentación del libro de Ulises SCHMILL, Los lenguajes de la jurisprudencia, la sociología y la ética, Valencia, Tirant lo Blanch, 2016, en el Instituto Tecnológico Autónomo de México (ITAM), Ciudad de México, 25 de febrero de 2016. 


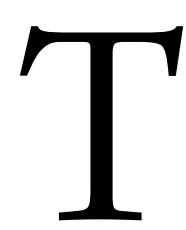

erminé de leer este penúltimo libro de Ulises SCHMILL, y como se lo expresé verbalmente, me parece una obra de gran originalidad, una síntesis de la ciencia en la mejor tradición kantiana, y, sin duda, un libro sumamente provocador. Quiero centrar mi intervención en un tema que ocupa y preocupa a Ulises SCHMILL, desde los ochenta, y que aparece y reaparece en una serie de libros hasta este último que comentamos: el problema de la justificación del castigo y sus relaciones con el poder. Los libros que he tomado en consideración son: La conducta del jabali $(1983,2005)$, Macbeth, la tragedia del poder (retoma su análisis de MACBETH en La conducta del Jabalí, pero ahora con el lente de la versión cinematográfica de Roman POLANSKI), El debate sobre Mitilene (1998), Teoría del derecho y del Estado (2003), Las implicaturas del resentimiento. La tragedia de Otelo (2010) y, en el que hoy nos reúne. SCHMILL se mueve con inteligencia y soltura a través de las obras de Tucídides, KAFKA, KelSEn, SKinNer, Weber, entre otros, y, por supuesto de su admirado SHAKESPEARE: Macbeth, Ricardo III, Otelo, El rey Lear, El mercader de Venecia [...]. De la mano de Ulises me he propuesto leer, en este año conmemorativo, la obra de SHAKESPEARE. Un agradecimiento extra que debo a la lectura de su obra y a su infatigable curiosidad intelectual.

Una de las ideas directrices en la obra de SCHMiLL es la distinción entre lo que, siguiendo a Max WEBER, se conoce como «ética de la convicción» y «ética de la responsabilidad». Esta distinción sirve de marco teórico para determinar dos modelos explicativos de decisiones y, con ellos, dos modelos posibles de interpretación jurídica ${ }^{1}$. Recordemos con SCHMiLL el texto de WeBER:

Pero sí hay una diferencia abismal entre obrar según la máxima de una ética de la convicción, tal como la que ordena (religiosamente hablando) «el cristiano obra bien y deja el resultado en manos de Dios» o según una máxima de la ética de la responsabilidad, como la que ordena tener en cuenta las consecuencias previsibles de la propia acción [...]. Cuando las consecuencias de una acción realizada conforme a una ética de la convicción son malas, quien la ejecutó no se siente responsable de ellas, sino que responsabiliza al mundo, a la estupidez de los hombres o a la voluntad de Dios que los hizo así. Quien actúa conforme a una ética de la responsabilidad, por el contrario, toma en cuenta todos los defectos del hombre medio².

Ambos modelos sirven también para dar cuenta de dos tendencias observables en la conducta humana. La primera tiene que ver con los intereses del sujeto sancionador, buscando su satisfacción en la retribución; la segunda tiene por objeto obtener la explicación de la conducta delictiva. SCHMILL las denomina «actitud normativa» y «actitud explicativa», respectivamente. La «actitud normativa» responde a una ética de la convicción, mientras que la «actitud explicativa» responde a una ética de la responsabilidad. La primera es metafísica, la segunda es científica. De acuerdo con SCHMILL, KANT sería el representante idóneo para ejemplificar la primera tendencia, así como AUSTIN, si Ulises está de acuerdo, podría ser un digno representante de la segunda. Detengámonos un poco en cada uno de estos modelos normativos, de acuerdo con la interpretación de SCHMILL, veamos algunas de sus consecuencias, y me reservo para el final algunos comentarios críticos que podrían dar lugar, creo, a un tercer modelo.

1 Vid. U. SCHMILL, «Interpretación del derecho y concepciones del mundo», en Teoría del derecho y del Estado, México, Porrúa, 2003.

2 Ibid., 212-213. 


\section{1. ÉTICA DE LA CONVICCIÓN O MODELO «CLEÓN-ABSOLUTISTA», O TAMBIÉN, «EL NOBLE SUEÑO DE ARIEL»}

De forma clara y detallada SCHMILL sintetiza las características típicas de la ética de la convicción en las siguientes tesis:

- Lo debido de una conducta nunca se encuentra determinado por las situaciones externas sino por las condiciones internas del sujeto.

- La desatención al mundo externo produce una tendencia despreciadora del empirismo y una proclividad al apriorismo y al absolutismo.

- El criterio fundamental de lo bueno consiste en seguir al pie de la letra la máxima o norma moral de la conducta.

- Dogmatismo en relación con las normas.

- Autocracia como correlato político ${ }^{3}$.

Esta ética de la convicción se ejemplifica en su exquisito libro, El debate sobre Mitilene, con el discurso de Cleón. Como se recordará, la materia del debate, tal como se presenta por TuCíDIDES, fue la dilucidación del problema de la justificación de la pena, de la fundamentación de la sanción o de la legitimidad del castigo ante la rebelión de los mitilenios. En palabras de SCHMILL:

El discurso de Cleón ha tendido a justificar la pena máxima impuesta a los mitilenios, mediante el señalamiento enfático de su culpa [...]. La culpa es la manifestación de la maldad y, por tanto, la medida de la pena. Ese es un argumento emotivo, dirigido a suscitar los sentimientos de los oyentes, para moverlos a la venganza. La compensación de la culpa por medio del castigo es una idea falsa y demagógica: la culpa no puede remediarse, no se puede intervenir en los acontecimientos pasados, como Protágoras lo había demostrado. La culpa tiene un supuesto indemostrable: que el sujeto infractor pudo haber actuado de otra manera ${ }^{4}$.

Bajo tales premisas, la concepción de Cleón es calificada por SCHMILL de tradicional, absolutista, retributiva y pasional, y corresponde, en sus propios términos, a la triada: pasado-pasión-justicia:

La justicia es entendida como retribución, como reacción violenta a un mal que se ha sufrido; por tanto, está condicionada por el pasado. La mirada de la retribución está dirigida hacia lo ya acontecido y está cargada con la sustancia del entusiasmo, generada por el deseo de venganza. La justicia, como retribución, satisface la pasión elemental de restablecer la igualdad rota entre los dolores y satisfacciones comparados intersubjetivamente, que son el lote de cada sujeto en su vida ${ }^{5}$.

¿Quién mejor que SHYLOCK, en El mercader de Venecia, para ejemplificar esta primera triada retribucionista? Recordemos el contrato en boca de SHYLOCK:

[...] me firmaréis alli simplemente vuestro pagaré, y a manera de broma será estipulado que, si no pagáis tal dia, en tal lugar, la suma o las sumas convenidas, la penalidad consistirá en una libra exacta de vuestra hermosa carne (a pound of flesh), que podrá ser escogida y cortada de no importa qué parte de vuestro cuerpo que me plazca.

3 Ibid., 216-218.

4 U. SCHMILL, El debate sobre Mitilene. La justificación de las penas, México, Verdehalago, 1998, 51 y 61.

5 Ibid., 66. 
Y aun cuando se le hace a SHYLOCK un ofrecimiento pecuniario muy tentador, ante la imposibilidad de Antonio para cumplir el contrato y someterse a tal predicamento, la respuesta no se hace esperar:

Aunque dividieras cada uno de ellos en seis, no lo aceptaría. Quiero que se cumpla el contrato [...]. Si no me la dais, maldigo de las leyes de Venecia, y pido justicia. ¿Me la dais? ¿sio no? ${ }^{6}$.

Tiene razón ScHMILL en resaltar las desventajas de una ética retribucionista, que bien pueden sintetizarse en la idea de que es muy difícil aceptar el hecho de que la suma de dos males dé como resultado un bien. En este sentido, las siguientes preguntas resultan pertinentes:

¿Qué sino el resentimiento y el deseo de venganza explica esta preferencia por un estado del mundo en que los males se multiplican, sin atender a la posibilidad de algún efecto benéfico para alguien? ¿No es acaso la demostración más clara del fetichismo ante las reglas propia del formalismo moral [y jurídico] toda esta idea de que los criminales deben ser penados cualesquiera que sean las consecuencias? («aunque perezca el pueblo», como decía KANT) ${ }^{7}$.

Y son precisamente las pasiones del resentimiento, la ira, la venganza las que mueven a esos personajes sublimes de SHAKESPEARE: recordemos la ira y el resentimiento de Shylock hacia Antonio, por su condición de judío:

Señor Antonio, innumerables veces me habéis reprendido en el puente de Rialto por mis préstamos y usuras, y siempre lo be llevado con paciencia, y he doblado la cabeza, porque ya se sabe que el sufrimiento es virtud de nuestro linaje. Me has llamado infiel y perro; y todo esto solo por tu capricho, y porque saco el jugo de mi hacienda, como es mi derecho.

De igual manera, es el resentimiento de Otelo por el color de su piel; y son las deformidades de Ricardo III; o la condición de bastardo de Edmundo, en El Rey Lear. Vengarse ante el mundo, buscar la culpabilidad en el otro, por estas condiciones indeseadas. No me resisto a citar estas palabras de Edmundo en El Rey Lear:

Tú eres mi diosa, Naturaleza; a tus leyes subordino mis acciones; no be de atenerme a la perniciosa costumbre y leyes de los Estados que pretenden desheredarme porque nací doce o catorce lunas después de mi hermano. ¿Por qué bastardo, por qué menos, si mis miembros están tan bien trabados, mi espiritu es tan generoso y mi aspecto tan noble como en el vástago de la esposa honrada [...]. ¿Por qué bastardos, si el lascivo calor de la Naturaleza puso en nosotros más vida y más vigorosa calidad que suele, en el triste, acostumbrado y tedioso tálamo, donde se procrea la dilatada raza de los tontos entre un dormir y un despertar?

Desde el punto de vista político, la ética de la convicción justifica un modelo tradicional y absolutista. Este modelo, que critica SCHMILL, es el que tiene en mente, por ejemplo, Isaiah BERLIN para caracterizar con tales calificativos lo que desde PLATÓN denomina la Central Western Tradition, con su imagen plástica del Templo de Zoroastro en La Flauta Mágica ${ }^{8}$. He simbolizado esta tradición con el Ariel de La Tempestad y la metáfora del «noble sueño» de Herbert HART ${ }^{9}$. Tales estructuras formalistas y dogmáticas serían las propias de un Estado «autocrático».

\footnotetext{
6 Vid. U. SchmiLl, Los lenguajes de la jurisprudencia, la sociología y la ética, 158-165.

7 C. S. NinO, Introducción al análisis del derecho, Buenos Aires, Astrea, 1980, 429-430.

8 I. BERLin, Four Essays on Liberty, Oxford University Press, 1969, 154.

9 H. HART, El concepto de derecho, Buenos Aires, Abeledo Perrot, 1963, cap. VII.
} 


\section{2. ÉTICA DE LA RESPONSABILIDAD O MODELO «DIÓDOTO-UTILITARISTA», O TAMBIÉN, «LA PESADILLA DE CALIBÁN»}

Las propiedades características de una ética de la responsabilidad, por contraposición a las de una ética de la convicción, según SCHMILL, podrían resumirse en las siguientes:

- Lo debido de una conducta se encuentra determinado por las situaciones exteriores.

- La atención al mundo externo produce una tendencia favorable al empirismo y una proclividad a rechazar el apriorismo y el absolutismo.

- El criterio fundamental de lo bueno consiste en seguir las reglas o máximas morales que tienden a considerar lo bueno o lo útil de las consecuencias y resultados externos de la propia conducta, para el sujeto actuante o para los demás.

- Con ello, se establece un criterio relativo de lo que es lo bueno.

- Si las éticas de la responsabilidad tienen las características de ser relativas, empíricas y antidogmáticas, entonces necesariamente, por razones de congruencia, sus partidarios sustentarán la democracia, la que se convierte en su correlato político ${ }^{10}$.

Tal ética de la responsabilidad se ejemplifica en El debate sobre Mitilene con el discurso de Diódoto. El contenido del discurso puede sintetizarse en los siguientes términos:

... la conveniencia y utilidad del castigo impuesto a los mitilenios. Utilidad y conveniencia ¿para quién? Evidentemente, para el imperio ateniense, para el poderoso. Diódoto se presenta más radical que los propios atenienses indignados: la utilidad será el criterio del castigo de los mitilenios, no el de la culpa [...]. Diódoto concibe al hombre como un ser guiado por las necesidades. Estas son las que determinan su conducta, prima facie ${ }^{11}$.

A diferencia de la argumentación de Cleón, la de Diódoto corresponde a la triada: futuro-razón-utilidad. A la justicia se opone la utilidad. Lo que se propone ahora es no mirar al pasado, poner al margen la pasión y olvidar la retribución. De lo que se trata es de actuar racionalmente y, en consecuencia, ponderar la utilidad de la conducta presente medida por sus consecuencias futuras:

la razón no está de parte de la retribución, sino de la utilidad. La culpa es un concepto al servicio de la retribución y es, por tanto, irracional. Afirmarla es el producto de haber asumido la postura normativa, la cual está al servicio del egoísmo mal entendido, pues con ello se niega el incremento de poder que puede producir el conocimiento y la racionalidad ${ }^{12}$.

Por supuesto, nada impide pensar que esa racionalidad sea usada estratégicamente en aras de la adquisición y preservación del poder para el sujeto actuante, y quizás, con un dejo de cinismo, en beneficio del bienestar general. Y aquí la genialidad de SHAKESPEARE asoma, de nueva cuenta, con una brillantez única: los mejores modelos consecuencialistas, sobre la base de un egoísmo racional, encarnan en la crueldad de Ricardo III; en la malevosidad de Yago, en Otelo; en el pragmatismo de Edmundo, en El Rey Lear.

\footnotetext{
10 U. SCHMILL, «Interpretación del derecho y concepciones del mundo», 218-220.

11 U. SCHMILL, El debate sobre Mitilene. La justificación de las penas, 64, 70-71.

12 Ibid., 80.
} 
El argumento presentado por Diódoto es de tipo utilitarista. Bajo esta concepción, SCHMILL no tendría inconveniente en aceptar, por ejemplo, que el AED y, específicamente, su propuesta de análisis económico de la sanción, parece ser un buen aliado de una ética de la responsabilidad. Hay una simpatía de SCHMILL por esta corriente, que al menos en su vertiente más empirista emparenta muy bien con la propuesta conductista de nuestro autor ${ }^{13}$. Cito a SCHMILL:

Desde el punto de vista de la terminología de los economistas podría decirse que la realización de la conducta infractora se lleva a cabo porque arroja una utilidad al sujeto infractor, superior a los costos en los que incurre con motivo de su ejecución. La diferencia entre las utilidades que obtiene el infractor y los costos en los que incurre, es positiva. El infractor se comporta desde el punto de vista económico, como un hombre racional, como un empresario del crimen: calcula sus costos y las utilidades esperadas. Si estas superan a aquellos realizará la conducta. Se trata de la ley de la oferta y la demanda ${ }^{14}$.

No deja de haber algo tenebroso en este juego del mercado: una ley que puede devorar y corromper sin ningún límite ético. Una suerte de Calibán (de caníbal) en $L a$ Tempestad, que he caracterizado bajo la metáfora de «la pesadilla», en los términos de Herbert HART.

¿Cuál fue el resultado del debate sobre Mitilene? Venció la proposición de Diódoto. Reflexión de SCHMILL en un pasaje modélico de argumentación consecuencialista:

¿Qué provecho obtendrían los atenienses con pasar a cuchillo a toda la población de Mitilene y vender como esclavos a las mujeres y a los niños? Con ello, no se destruiría o repararía lo ya acontecido. Previendo lo que podía traer el futuro, quizás lo más conveniente fuera revocar la sentencia de muerte e imponer una fuerte multa a Mitilene, para reparar el daño causado y, además, obligar a pagar anualmente un tributo como miembro de la Confederación de Delos ${ }^{15}$.

Si se parte de una visión consecuencialista y se rechaza algún límite objetivo, no debe sorprendernos que la decisión de los atenienses, dos años después, haya sido la contraria a la sustentada con respecto a los mitilenios, pero ahora contra los melios:

Y los atenienses, dice TucíDIDES, ejecutaron a todos los melios en edad viril que cayeron en sus manos y redujeron a la esclavitud a los niños y mujeres. Fueron ellos mismos quienes, enviando seguidamente quinientos colonos, poblaron la ciudad ${ }^{16}$.

Ante tal hecho, la reflexión de SCHMiLL es concluyente:

Los mismos atenienses que decidieron la revocación de la sentencia de muerte en contra de los mitilenios, dos años después ejecutaron el acto que entonces no se atrevieron a realizar. Algo muy grave debió haber sucedido entre estos dos acontecimientos, pues en el caso de los melios ni siquiera hubo una rebelión en el sentido estricto de la expresión, pues esta pequeña comunidad doria era una colonia de Esparta [...]. Era como si el espíritu de Cleón se hubiera apoderado de Atenas ${ }^{17}$.

Con un criterio de racionalidad instrumental, en un contexto consecuencialista puede justificarse cualquiera de las dos sanciones si así ha sido consensuada por con-

13 Vid. U. SCHMILL, La conducta del Jabalí, México, UNAM, 1993; reedición corregida en Ediciones Coyoacán, México, México, 2005.

${ }^{14}$ U. SCHMILL, «Interpretación del derecho», 70-71.

15 U. SCHmill, El debate sobre Mitilene. La justificación de las penas, 83-84.

16 Citado por U. ScHMiLL, ibid., 87-88.

17 Ibid., 88. 
veniencia para los atenienses. Una posible razón, sugerida por el propio TuCíDIDES en el texto, podría haber sido la necesidad de expansión territorial y poblacional en un marco imperialista. En un tiempo $x$ se perdona y se aplica una sanción «relativa» (mitilenios); en un tiempo $y$, por otras razones, conviene aplicar una sanción «absoluta» (melios). ¿Cuál es el límite? Si no se apelan a otro tipo de razones, no solo cualquiera de las dos soluciones contrapuestas son posibles, sino que ambas podrían justificarse ética y jurídicamente.

Hasta aquí la presentación de los dos modelos en la interpretación de SCHMILL. Pues bien, creo que entre el modelo Cleón-absolutista y el modelo Diódoto-utilitarista, entre Ariel y Calibán, cabe una tercera posibilidad.

\section{3. ÉTICA DE LA COOPERACIÓN O MODELO «PERICLES-OBJETIVISTA», O TAMBIÉN, «LA VIGILIA DE PRÓSPERO»}

Por lo pronto, no puedo más que compartir el rechazo enfático de SCHMILL al absolutismo y al realismo moral de una ética de la convicción, y a esas formas de fanatismo, dogmatismo, arbitrariedad e irracionalidad que hacen depender el discurso de dogmas no sujetos a criterios empíricos y racionales. Pero si bien estos productos de una ética de la convicción son criticables, creo también que sus desventajas no deben impedir ver algunas de sus bondades, por ejemplo: exigir solo la penalización de acciones voluntarias, prescribir penas más severas para los hechos más graves, determinar que un acto intencional sea más severamente penalizado que uno negligente, excluir la posibilidad de penar a un inocente; aspectos todos ellos que corresponden también a nuestras convicciones intuitivas de justicia ${ }^{18}$. Más aún, el problema no está solo en la posibilidad de penar a los inocentes sino también en el castigo de los culpables. Porque:

[...] como según el utilitarismo, esa culpabilidad es irrelevante (salvo por razones de eficacia) para justificar la pena, los que han delinquido podrían legítimamente protestar: «¿Por qué hemos de ser sacrificados nosotros en aras del mayor beneficio del resto de la sociedad, o sea, en definitiva, de otros hombres? No nos digan que porque hemos cometido delitos, porque eso, según ustedes es tan moralmente irrelevante como nuestro color de piel. Ustedes nos están usando solo como medios en beneficio de otros» ${ }^{19}$.

Dicho lo anterior y con el ánimo de ajustarme al relato de TUCíDIDES, pienso que, quizás, el discurso fúnebre de Pericles, reconstruido por el propio historiador de $\mathrm{La}$ Guerra del Peloponeso, sería un buen ejemplo de este tercer modelo que propongo. Mientras en Diódoto se vislumbra la justificación de una racionalidad sofista de tipo instrumental, en el caso de Pericles, son la justicia y la igualdad ante la ley (isonomia) las que permean todo su discurso:

Tenemos un régimen político que no envidia las leyes de los vecinos y somos más bien modelo para algunos que imitadores de los demás. Recibe el nombre de democracia, porque se gobierna por la mayoría y no por unos pocos; conforme a la ley, todos tienen iguales

\footnotetext{
18 Vid. C. NinO, op. cit., 429.

19 Ibid., 430-431.
} 
derechos en los litigios privados y, respecto a los honores, cuando alguien goza de buena reputación en cualquier aspecto, se le honra ante la comunidad por sus méritos y no por su clase social; y tampoco la pobreza, con la oscuridad de consideración que conlleva, es un obstáculo para nadie, si tiene algún beneficio que hacerle a la ciudad [...]. Y así como no nos molestamos en la convivencia privada, tampoco transgredimos la leyes en los asuntos públicos, sobre todo por temor, con respecto a los cargos públicos de cada ocasión y a las leyes y, entre estas, particularmente, a las que están puestas en beneficio de las víctimas de la injusticia y a las que, aun no escritas, conllevan por sanción una vergüenza comúnmente admitida $^{20}$.

Entre el absolutismo moral y el subjetivismo cabe la posibilidad de un objetivismo (mínimo) muy ajeno al dogmatismo y, por el contrario, anclado fuertemente en premisas empírico-racionales, en el marco de una tradición hobessiana-kantiana. No cualquier alejamiento del subjetivismo nos conduciría irremediablemente a un absolutismo moral. Ambas tradiciones, la hobessiana y la kantiana, aparecen conectadas en lo que podríamos llamar «la práctica social de la discusión moral» ${ }^{21}$ que, por una parte, satisface ciertas funciones relacionadas con la superación de conflictos y el facilitamiento de la cooperación a través del consenso y, por otra, comprende ciertos presupuestos procedimentales y aun sustantivos - derechos humanos exigibles como precondiciones del propio discurso moral - apropiados para satisfacer tales funciones.

Sorprendentemente, en su libro Las implicaturas del resentimiento. La tragedia de Otelo, SCHMILL cierra su argumentación con algunas reflexiones que se ajustan a este tercer modelo y que respiran un aire de optimismo. Al final de la tragedia de Otelo, lo sabemos, este termina apuñalándose. Cassio es nombrado gobernador de la isla y se le pide que sentencie al malvado de Yago. ¿Cómo se transita del secreto y la oscuridad a la luz de la verdad en el juicio? La respuesta de US es clara: «Por la apertura hacia el exterior, por la confrontación de pequeños trozos de información con otros que tenían otras personas diferentes al círculo de Otelo y de Yago». Todo ello en un ejercicio de «composibilidad», siguiendo a Leibniz, para garantizar la imparcialidad «desde arriba». Se trata dice US de «la construcción social del conocimiento y la objetividad». SCHMILL asume un construcitivismo sobre bases objetivas. Más aún, sigo citando a Ulises SCHMILL, en un pasaje digno de ponerse en boca de Pericles:

Se trata de la instauración de la verdad por medio de los testimonios de una sociedad abierta. Esto tiene ecos con la gran obra de Esquilo, Las Euménides, en donde la diosa Atenea estableció por vez primera el tribunal griego del Areópago, para resolver, con la relativa objetividad posible de un tribunal independiente, la culpa de Orestes por el asesinato de su madre, dejando atrás la venganza privada retributiva, cargada de subjetivismo ${ }^{22}$.

Independencia, imparcialidad, objetividad, en el contexto de una «sociedad abierta» (SCHMILl tiene en mente a Karl Popper). Vale decir, entonces, que a las triadas: pasado-pasión-justicia y futuro-razón-utilidad podría agregarse una tercera, pasado-razón-justicia, en el marco de un Estado democrático y constitucional de derecho como único garante de la paz futura. Esta, me parece es la alternativa que abre ese personaje tan enigmático de SHAKESPEARE, en esa tragedia tan peculiar en el conjunto de su obra,

${ }^{20}$ Tucídides, Historia de la guerra del Peloponeso, II, 37, edición de Luis M. Macía Aparicio, Madrid, Akal, 1989, 150-151.

21 Vid. C. S. NinO, Ética y derechos bumanos, Buenos Aires, Astrea, 1989, 104 y ss.

22 U. SCHMiLl, Las implicaturas del resentimiento. La tragedia de Otelo, México, Themis, 2010, 121-122. 
y que vengo citando, que es La Tempestad: un hechicero agnóstico que propone el perdón y la reconciliación. Y remarco lo de agnóstico porque Próspero no está preocupado por las sanciones o el castigo trascendente. No de otra forma entiendo esa frase conocida y cargada de tanta fuerza expresiva: «Somos de la sustancia de la que están hechos los sueños; y nuestra pequeña vida culmina en un dormir». Si hay que hacer justicia se hace en esta vida, aquí y ahora, por ello: «La grandeza está en la virtud no en la venganza. Si se han arrepentido, la senda de mi plan no ha de seguir con la ira».

Pero si bien Próspero abre la posibilidad del perdón y la reconciliación, no me alcanza para el castigo. Tengo que llamar a Pericles porque solo en el marco de «las leyes para los asuntos públicos» y «entre estas, particularmente, a las que están puestas en beneficio de las víctimas de la injusticia», se justifica el castigo de los culpables. Pero no un castigo prudencial en la línea utilitarista, sino un castigo moderadamente retribucionista, porque si las personas consideran que no se toma en serio su condición de víctimas, se producen dos consecuencias inaceptables: a) se sienten doblemente dañadas porque no solo han sufrido la acción del agresor sino que, además, sufren el daño psicológico de sentirse indefensas frente al agresor real o potencial, y b) pueden verse impulsadas a ejercer justicia por cuenta propia. En el primer caso se viola el principio de equidad, en el segundo el principio de seguridad ciudadana, y ambos principios son constitutivos de un Estado constitucional de derecho ${ }^{23}$.

No sé qué ha pasado en estos últimos años, pero diría que al optimismo en Las implicaturas del resentimiento, regresa SCHMILL a un pesimismo, que él mismo anticipa ya desde el prólogo del libro que hoy comentamos y que, en efecto, se confirma en las páginas finales con una crítica radical a la ética de la convicción. La consecuencia natural de esta, piensa SCHMILL, es la «banalidad del mal», en los términos de H. Arendt ${ }^{24}$. Quizás, la pretensión epistemológica de dar unidad a la ciencia, obligó a cerrar la pequeña puerta que había dejado abierta en Las implicaturas y por la que me parece se podría haber comenzado a transitar a un tercer modelo que evitara los excesos criticables de una ética de la convicción y también, los de una ética de la responsabilidad.

23 Vid. E. Garzón VALDÉs, «Terrorismo de Estado y justicia», Estudios, México, ITAM, 1991, 16.

24 U. SCHMILL, Los lenguajes de la jurisprudencia, la sociología y la ética, 11-14 y 184-185. 